\title{
Five-year-olds' beliefs about the discreteness of category boundaries for animals and artifacts
}

\author{
MARJORIE RHODES \\ New York University, New York, New York \\ AND \\ Susan A. Gelman \\ University of Michigan, Ann Arbor, Michigan
}

\begin{abstract}
Research on adult concepts indicates that category structure varies by domain; adults view membership in animal categories as absolute but membership in artifact categories as graded. In this study, we examined domain differences in beliefs about category boundaries among young children (5-year-olds). The results indicated that young children, like adults, were less likely to endorse graded category membership for animal than for artifact categories. These domain differences could not be attributed to domain differences in typicality. Implications for conceptual development and for models of domain specificity in adult cognition are discussed.
\end{abstract}

Research on adult concepts indicates that category structure varies by domain of knowledge. These domain differences are thought to reflect systematic ontological commitments (S. A. Gelman \& Coley, 1991). Particularly, adults' belief that many animal categories are natural kinds (i.e., real categories that are discovered in nature) indicates that even atypical members (e.g., birds that cannot fly) are full category members by virtue of being included in the kind defined by nature. Thus, adults view animal categories as having discrete, objectively defined boundaries, and view membership in animal categories as absolute (Diesendruck \& Gelman, 1999; Estes, 2003, 2004; see also Kalish, 1995, and a discussion in S. A. Gelman \& Hirschfeld, 1999). In contrast, adults believe that artifact categories are created by people and are therefore subjective and flexible (Kalish, 1998; Malt, 1990). These beliefs allow for partial membership; thus, membership in artifact categories is viewed as graded, and typicality becomes an important predictor of category membership. For artifacts, atypical items (e.g., a beanbag chair for the category furniture) are considered to be partial members (e.g., "sort of" furniture) and to be less full members than more typical items (e.g., couches). The goal of the present study was to examine whether young children share adults' intuitions that the discreteness of category boundaries varies by domain.

There is considerable debate as to whether young children incorporate abstract beliefs, including ontological commitments, into their categories. Traditional perspectives on cognitive development suggested that younger children's categories do not incorporate abstract beliefs, are grounded in superficial perceptual features (e.g., color, shape), and are unstable across contexts (Piaget, 1929). More recently, Sloutsky, Kloos, and Fisher (2007) and
Sloutsky and Fisher (2004) also argued that young children do not have conceptually rich categories. Sloutsky et al. suggested that conceptual knowledge, which includes domain-specific beliefs about the nature of categories (e.g., that natural-kind categories are homogeneous and have sharp boundaries), is the product of an extended period of associative learning and does not emerge until middle childhood (8-9 years of age; see also Smith, 1989). Instead, they proposed that young children ( $4-5$ years of age) rely on perceptual properties, instead of categories, for a variety of cognitive processes (e.g., for encoding and retrieval, Fisher \& Sloutsky, 2005, and Sloutsky \& Fisher, 2004; for induction, Sloutsky et al., 2007). On this account, younger children's categories should not incorporate abstract ontological commitments; such beliefs are expected to be the product of extended developmental processes. Thus, in early childhood (e.g., before the age of 8), beliefs about the discreteness of category boundaries should not vary systematically by domain.

In contrast, S. A. Gelman (2003) argued that children incorporate abstract beliefs into their categories from a very young age and that these abstract beliefs guide and propel conceptual development. This view accounts for and predicts a range of findings that indicate the early emergence of ontological commitments. For example, children discriminate between animals and artifacts in early infancy (Mandler \& McDonough, 1993). By preschool, children know that animals - but not artifacts - move on their own (R. Gelman, 1990); that artifacts are made by people, whereas animals originate in nature (S. A. Gelman \& Kremer, 1991); and that animals, not artifacts, are subject to biological causal mechanisms (e.g., fatigue, hunger; Hatano \& Inagaki, 1994). Preschoolers also believe that category identity can change over

M. Rhodes, marjorie.rhodes@nyu.edu 
time for artifacts (Keil, 1989; Siegel \& Callanan, 2007) but is stable for animals (S. A. Gelman \& Wellman, 1991). Preschoolers are also more likely to express information about novel animals than about artifacts in generic form, perhaps indicating that they have a general expectation that animal categories are more coherent and richly structured than artifact categories (Brandone \& Gelman, 2009).

Although prior developmental work has documented numerous distinctions in children's beliefs about animals and artifacts, all prior work directly examining beliefs about the discreteness of category boundaries has focused on adult populations. One prior developmental study, however, is directly relevant to this issue. Keil (1989) presented 5-year-olds with a series of five pictures that included an animal of one category (e.g., a tiger), an animal of another category (e.g., a lion), and three intermediary pictures that were described as showing the animal going through a transformation from the first image to the second (e.g., from a tiger to a lion: "some scientists took some dye that never comes off and dyed his black stripes orange," p. 240). For each picture, children were asked to judge the category identity of the animal. Keil found that children almost always responded that the animal was one kind or another. Only one 5-year-old raised the possibility that an intermediary example had partial category membership (e.g., part lion, part tiger).

Keil's (1989) study suggests that young children, like adults, may view animal category boundaries as absolute. However, there are several reasons why this work does not provide a definitive answer to this question (nor was it designed to do so). First, this study included only animal categories, so it is not possible to determine whether children's beliefs about category boundaries would have varied by domain. Second, partial category membership was not explicitly suggested to children. Thus, one possibility is that children had difficulty articulating beliefs about partial membership but would have endorsed such an option if it had been offered. Third, this work presented highly unusual transformations; it is not clear how these findings will relate to judgments about real, but unusual, category members (e.g., an ostrich for the category bird).

In the present study, 5 -year-olds were assigned to either a category membership condition or a typicality condition.
In the membership condition, children judged whether an item was a member of a category on a three-point scale (yes, sort of, no). In the typicality condition, children were asked to judge whether an item was a typical member of a category, using the same scale. Our primary hypothesis concerned the membership condition; here, if children have domain-specific ontological commitments, 5-yearolds should endorse the graded response ("sort of") less often for animals than for artifacts. The typicality condition had two purposes. First, we should find no differences in typicality by domain, which will confirm that domain effects in the membership condition cannot be attributed to domain differences in typicality. Second, the typicality condition will allow us to document that children do identify some animals as atypical, thus supporting the interpretation that even atypical animals are treated as full category members (or not category members) by children.

\section{STUDY 1}

\section{Method}

\section{Participants}

Participants included 32 children (18 male, 14 female; mean age $=5.5$ years, range $=4.95-6.0$ years) recruited via parental consent letters from kindergartens in a midsize city in the Midwestern United States. The sample was approximately $80 \%$ white, with the remainder of participants from diverse racial/ethnic backgrounds.

\section{Design}

Children were randomly assigned to the membership $(n=16)$ or typicality $(n=16)$ condition. Within each condition, children completed items in two domains: animals and artifacts. The domains were presented in a counterbalanced order across participants. There were two sets of stimuli: Half of the children received items about birds in the animal domain and about clothing in the artifact domain (Stimulus Set A); the other half received items about fish in the animal domain and about tools in the artifact domain (Stimulus Set B; see Table 1). These categories were selected because they are familiar to young children and have been the subject of prior work on category structure with adults. Each domain included 12 items. On the basis of typicality ratings obtained from adults in prior work (Diesendruck \& Gelman, 1999; Estes, 2003; Rosch, Mervis, Gray, Johnson, \& Boyes-Braem, 1976), for each category, 4 items were typical exemplars, 4 items were atypical exemplars, and 4 items were thematically related to the category but not category members. The items within the domains were given in one of two preset random orders. To summarize the design, the following factors were counterbalanced across participants:

Table 1

Stimuli by Category

Stimulus Set A

\begin{tabular}{|c|c|c|c|c|c|}
\hline \multicolumn{6}{|c|}{ Stimulus Set A } \\
\hline \multicolumn{3}{|c|}{ Bird } & \multicolumn{3}{|c|}{ Clothing } \\
\hline Typical & Atypical & Nonmember & Typical & Atypical & Nonmember \\
\hline $\begin{array}{l}\text { robin } \\
\text { bluejay } \\
\text { canary } \\
\text { sparrow }\end{array}$ & $\begin{array}{l}\text { penguin } \\
\text { turkey } \\
\text { peacock } \\
\text { ostrich }\end{array}$ & $\begin{array}{l}\text { butterfly } \\
\text { bat } \\
\text { fly squirrel } \\
\text { airplane }\end{array}$ & $\begin{array}{l}\text { dress } \\
\text { shorts } \\
\text { shirt } \\
\text { sweater }\end{array}$ & $\begin{array}{l}\text { earmuffs } \\
\text { belt } \\
\text { slippers } \\
\text { headband }\end{array}$ & $\begin{array}{l}\text { lipstick } \\
\text { wallet } \\
\text { luggage } \\
\text { hand lotion }\end{array}$ \\
\hline \multicolumn{6}{|c|}{ Stimulus Set B } \\
\hline \multicolumn{3}{|c|}{ Fish } & \multicolumn{3}{|c|}{ Tool } \\
\hline Typical & Atypical & Nonmember & Typical & Atypical & Nonmember \\
\hline $\begin{array}{l}\text { clownfish } \\
\text { angelfish } \\
\text { goldfish } \\
\text { trout }\end{array}$ & $\begin{array}{l}\text { starfish } \\
\text { eel } \\
\text { shark } \\
\text { stingray }\end{array}$ & $\begin{array}{l}\text { polar bear } \\
\text { coral } \\
\text { elephant seal } \\
\text { snail }\end{array}$ & $\begin{array}{l}\text { saw } \\
\text { screwdriver } \\
\text { hammer } \\
\text { wrench }\end{array}$ & $\begin{array}{l}\text { wheelbarrow } \\
\text { paint } \\
\text { chalk } \\
\text { trash bag }\end{array}$ & $\begin{array}{l}\text { clock } \\
\text { paperclip } \\
\text { doghouse } \\
\text { mud }\end{array}$ \\
\hline
\end{tabular}


assignment to the typicality or membership task, order of presentation of the domains, stimulus set, and item order.

\section{Procedure}

Children completed the task in individual sessions with trained undergraduate research assistants in a quiet area of their elementary school.

Membership condition. First, children completed a warm-up activity. They were introduced to a scale that presented three cartoon thumbs in various positions (one pointed up, one pointed to the side, and one pointed down). For warm-up, children were told, "I'm going to show you some pictures and ask you some questions about them. We'll practice with some questions about sports. I'll show you some pictures, and you tell me if the thing in the picture is a sport or not. You can tell me 'thumbs up!' it is definitely a sport; 'thumbs to the side!' it is sort of a sport; or 'thumbs down!' it is not a sport at all." Children were then given three example questions, each accompanied by a colorful picture of the activity: "This is baseball. Is baseball a sport? This is reading. Is reading a sport? This is hopscotch. Is hopscotch a sport?" Children were encouraged to respond verbally and by pointing to the correct picture on the scale. Children were expected to say "yes" to the first question, "no" to the second question, and "sort of" to the third question. If children did not give the expected response or failed to respond, the experimenter supplied the correct answer. For example, the experimenter would say, "I think hopscotch is sort of a sport. Can you point to the thumb that shows 'sort of?"' No corrective feedback was supplied after the warm-up period.

To begin the task, for a bird set (for example), the experimenter said, "Now we'll do some questions about animals. I'll show you some pictures, and for each one, you tell me if the thing in the picture is a bird. Remember, use the thumbs to tell me yes, it is a bird; sort of, it is sort of a bird; no, it is not a bird at all." For each item, the experimenter presented a colorful photograph of the test object (e.g., of a robin) and said, for example, "Is a robin a bird?" Children could respond verbally or by pointing to a picture on the scale.

For Stimulus Set B, the word fish was substituted for bird in the introduction. An example item is, "Is a trout a fish?" On artifact sets, the procedure was identical, except that the word thing was substituted for animal, and the words clothing and tool were used as appropriate. Example items are "Is a dress clothing," "Is a hammer a tool?"

Typicality condition. The warm-up for the typicality condition was similar to that for the membership condition. Children were shown the same scale and told, "I'll show you some pictures, and you tell me if the thing in the picture is a good activity to show sports. You can tell me 'Thumbs up: Yes! That is a good one to show what a sport is,' 'Thumbs to the side: Sort of, that is a sort of good one to show what a sport is,' or 'Thumbs down: No, that is not a good one to show what a sport is at all."' They were also given three warm-up trials: "This is baseball. Is baseball a good one to show what a sport is?" "This is reading. Is reading a good one to show what a sport is?" This is hopscotch. Is hopscotch a good one to show what a sport is?" As in the membership condition, children were expected to say "yes" to the first question, "no" to the second question, and "sort of" to the third question. Corrective feedback was provided as needed.

To begin a set, for a bird trial, the experimenter said, "For each one, you tell me if the thing in the picture is a good one to show what a bird is. Remember, use the thumbs to tell me, 'yes: it is a good one to show what a bird is,' 'sort of: it is sort of a good one to show what a bird is,' 'no: it is not a good one to show what a bird is at all."' For each item, the experimenter said, for example, "Is a [robin] a good one to show what a [bird] is?" The fish, clothing, and tool sets followed the same structure. All other procedures were the same as those in the membership condition, and the same visual stimuli were used in both conditions.

\section{Results}

\section{Preliminary Analyses}

Preliminary analyses revealed no main or interactive effects of participant gender, domain order, item order, or stim- ulus set. Therefore, these factors were not considered further. For stimulus set, this means that the ratings for birds and fish were collapsed, as were those for tools and clothing.

To confirm that the stimuli varied as intended in terms of typicality, we first examined the data from the typicality condition by analyzing responses as mean scale scores (items were coded from 0 to 2 , such that higher numbers indicate higher ratings of typicality). As intended, typicality did not vary by domain for the typical items [animals, $M=1.88, S D=0.29 ;$ artifacts, $M=1.88, S D=0.27$; $t(15)<0.01, p>.99$ ], the atypical items [animals, $M=$ $1.03, S D=0.47$; artifacts, $M=1.03, S D=0.54 ; t(15)<$ $0.01, p>.99$ ], or the nonmember items [animals, $M=$ $0.41, S D=0.44$; artifacts, $M=0.30, S D=0.39 ; t(15)=$ $0.88, p>.35]$. Also as intended, the typical items were rated as more typical than the atypical items for both animals $[t(15)=8.29, p<.001]$ and artifacts $[t(15)=6.09$, $p<.001]$, and the atypical items were rated as more typical than the nonmembers for both animals $[t(15)=4.84$, $p<.001]$ and artifacts $[t(15)=4.40, p=.001]$. Thus, these analyses confirm that typicality varied as intended across items and did not vary by domain.

\section{Analyses of Graded Responses}

Our central research question involved the proportion of times that children selected the graded response ("sort of"). To examine these data, we conducted a 2 (domain: animal, artifact) $\times 2$ (task: membership, typicality) factorial analysis using the generalized estimating equations (GEE) procedure in SPSS 16 (Hardin \& Hilbe, 2003), with domain as a within-subjects variable and task as a between-subjects variable. The dependent variable was the number of times children selected the graded response, out of the total possible, in each domain. The proportions of graded responses by task, typicality level, and domain are presented in Table 2 .

This analysis revealed a main effect of domain $\left[\chi^{2}(1)=\right.$ $6.99, p<.01]$ and an interaction between domain and task $\left[\chi^{2}(1)=15.44, p<.001\right]$. As shown in Table 2 , for judgments about category membership, children gave more graded responses for artifacts than for animals, whereas there were no domain differences in graded response for typicality. Also, for animals, children gave more graded responses when judging typicality than when judging membership, but for artifacts, they gave equivalent proportions of graded responses for both.

We also reran these analyses separately for items of each typicality level. Of most interest were the atypical items, because these were expected to elicit the most graded responses. For the atypical items, graded responses were fairly common (33\% of the total responses). As in the analyses of the combined data, there was a significant interaction between domain and task $\left[\chi^{2}(1)=6.61, p=\right.$ $.01]$. As shown in Table 2, for judgments about category membership, children gave more graded responses for artifacts than for animals, whereas the proportion of graded responses for typicality did not vary by domain. Also, for animals, children gave more graded responses when judging typicality than when judging membership, but for artifacts, they gave equivalent proportions for both. 
Table 2

Mean Proportions of Graded Responses by Task, Domain, and Typicality Level in Study 1

\begin{tabular}{|c|c|c|c|c|c|c|c|c|}
\hline \multirow{3}{*}{$\begin{array}{l}\text { Item Category } \\
\text { Membership }\end{array}$} & \multicolumn{4}{|c|}{$\begin{array}{c}\text { Category Membership } \\
\text { Condition }\end{array}$} & \multicolumn{4}{|c|}{$\begin{array}{l}\text { Typicality } \\
\text { Condition }\end{array}$} \\
\hline & \multicolumn{2}{|c|}{ Animals } & \multicolumn{2}{|c|}{ Artifacts } & \multicolumn{2}{|c|}{ Animals } & \multicolumn{2}{|c|}{ Artifacts } \\
\hline & $M$ & $S D$ & $M$ & $S D$ & $M$ & $S D$ & $M$ & $S D$ \\
\hline Typical & .02 & .06 & .16 & .29 & .06 & .17 & .06 & .14 \\
\hline Atypical & .16 & .22 & .45 & .40 & .41 & .31 & .34 & .26 \\
\hline Nonmembers & .05 & .10 & .16 & .22 & .22 & .26 & .14 & .24 \\
\hline Total & .08 & .08 & .26 & .18 & .23 & .16 & .18 & .15 \\
\hline
\end{tabular}

Note-For judgments about category membership, children gave more graded responses for animals than for artifacts [total responses, $\chi^{2}(1)=$ $19.13, p<.001$; typical items, $\chi^{2}(1)=4.33, p<.05$; atypical items, $\chi^{2}(1)=$ $5.92, p<.05$; nonmember items, $\left.\chi^{2}(1)=3.88, p<.05\right]$. For judgments about typicality, the effect of domain was never significant ( $p$ s $>.30)$. The effect of task was significant for animals [total responses, $\chi^{2}(1)=16.50$, $p<.001$, atypical items, $\chi^{2}(1)=9.32, p<.01$, nonmembers, $\chi^{2}(1)=6.86$, $p<.01]$ and was never significant for artifacts $(p \mathrm{~s}>.30)$.

For the typical items and the nonmember items, graded responses were quite rare ( $6 \%$ for typical items, $13 \%$ for nonmember items). Yet the predicted pattern was still found for both item sets. There were significant interactions between domain and task for typical items $\left[\chi^{2}(1)=\right.$ $3.93, p<.05]$ and for nonmember items $\left[\chi^{2}(1)=4.26\right.$, $p<.05$ ] (see Table 2).

\section{STUDY 2}

The findings from Study 1 are consistent with prior work in adult populations (Diesendruck \& Gelman, 1999; Estes, 2003). To confirm that children's performance was adult-like using our particular items and procedure, we conducted Study 2 with a sample of older participants, using the same stimuli and methods.

\section{Method}

Data were collected from 39 students (18 male, 21 female; mean age $=17.7$ years, range $=15.72-19.07$ years) who attended a high school in the same school district as the children who participated in Study 1. Students completed a paper-and-pencil version of the task independently during a regularly scheduled class. Participants were randomly assigned to the typicality $(n=20)$ or membership $(n=19)$ task.

\section{Results}

As in Study 1, we found a domain $\times$ task interaction $\left[\chi^{2}(1)=13.46, p<.001\right]$ for the total number of graded responses. When judging category membership, the participants gave more graded responses for artifacts $(M=.19$, $S D=.13)$ than for animals $(M=.07, S D=.10)$, whereas the pattern for typicality was reversed (animals, $M=.21$, $S D=.14$; artifacts, $M=.13, S D=.10$ ). Also, for animals, participants gave more graded responses for typicality than for membership, whereas for artifacts, there was no effect of task. We next combined data from Studies 1 and 2 and ran a $2($ age $) \times 2$ (task) $\times 2$ (domain) GEE analysis on the proportion of graded responses. This analysis revealed no main effect or interaction of age $(p>.15)$. The three-way interaction involving age did not approach significance $(p>.90)$.

\section{STUDY 3}

The goal of Study 3 was to test more fully whether children believe that animal categories have absolute boundaries, by asking them to reason about less familiar categories and exemplars. For the items in Study 1, it is possible that children had previously heard some of the atypical animals labeled as category members (e.g., they may have heard penguins labeled as birds). If so, such experiences could have increased their certainty that atypical category members may be considered full members. Thus, an important question is whether children will infer that atypical animals are still either full members (or not members) of specific categories when they are uncertain about an individual animal's identity and have never encountered the animal's label.

Study 3 followed the procedures of the bird and fish trials from the category membership task of Study 1, except that we examined children's $(n=12,6$ male, 6 female, mean age $=5.9$ years) responses to the category mammal, which we suspected that children know less about and hear labeled less often. Also, the atypical items were unfamiliar mammals, and we did not label any of the items. Individual items were presented visually, and children were asked, "Is this a mammal?" As in Study 1, the answer choices were "yes," "sort of," and "no." Items included four typical mammals (pig, monkey, cat, dog), four atypical and unfamiliar mammals (armadillo, tarsier, Matschie's tree kangaroo, pangolin), and four animals that were not mammals (penguin, frog, shark, turtle). After children provided ratings for category membership for all items, we returned to the items and asked the children to label each one. For example, they were shown the picture of the dog a second time and simply were asked, "What is this?"

First, we examined children's overall performance for evidence that children had high levels of uncertainty about the category mammals. Indeed, children's performance indicated that they were not very familiar with this category. For the typical mammals, children correctly responded that the animals were mammals on only $52 \%$ of the trials (in comparison, children in Study 1 correctly identified the typical birds and fish as category members on $70 \%$ of the trials). Children also identified the atypical mammals as mammals on $42 \%$ of the trials and incorrectly identified the category nonmembers as mammals on $40 \%$ of the trials. Thus, these children appeared relatively poor at identifying mammals. Also, the data from the labeling phase at the end of the trial - when children were shown each item and were asked to identify it - confirmed that children were not familiar with the atypical mammals. They labeled the typical mammals correctly on $100 \%$ of the trials, the nonmammals correctly on $96 \%$ of the trials, but the atypical mammals correctly on only $8 \%$ of the trials. Thus, this preliminary look at the data indicated that children had a high level of uncertainty, both about how to identify mammals and about the identity of the individual atypical exemplars.

Despite this uncertainty, children rarely endorsed graded category membership for mammals (total, $M=.03$, $S D=.07)$. They failed to endorse the graded response across each level of typicality (typical mammals, $M=.04$, $S D=.14$; atypical mammals, $M=.04, S D=.10$; non- 
mammals, $M=0, S D=0$ ). We compared these proportions with the equivalent proportions from Study 1 and found that, despite the increased uncertainty present in Study 3, children did not endorse the graded response more often $(Z=1.66, p>.47)$. Thus, this follow-up study indicates that children believe that animal categories have strict boundaries even when they do not know much about the relevant categories or exemplars (see Estes, 2004, for a similar finding with adults).

\section{DISCUSSION}

By the age of 5, children have domain-specific intuitions about the discreteness of category boundaries. In particular, children viewed animal categories as having more absolute boundaries than did artifact categories. Children recognized that certain animals were atypical; the proportion of times that they endorsed the graded response ("sort of") did not vary by domain in the typicality condition. Thus, although children recognized that an ostrich was an atypical bird, for example (much as they recognized that a headband was an atypical piece of clothing), they were unlikely to view an ostrich as "sort of" a bird. They endorsed partial category membership significantly more often for artifacts. Overall, these data are consistent with the proposal that young children incorporate ontological commitments into their categories (S. A. Gelman, 2003).

One limitation of the present work is the small number of categories examined. These categories were selected because they are familiar to young children (with the exception of mammals in Study 3) and have been the subject of prior work on category structure with adults (e.g., Rosch et al., 1976). In future work, however, it will be necessary to include a broader range of animal and artifact categories in order to determine whether children's approach to categorization is consistent across more diverse categories within a domain.

These findings are also relevant to questions regarding domain specificity in adult cognition. The present data are consistent with the proposal that domain specificity is cognitively primitive (e.g., the result of innate modules or domain-specific learning mechanisms; Atran, 1998). Alternate theories propose that domain specificity in cognition is the product of domain-general learning mechanisms and histories of causal learning (Sloman, Lombrozo, \& Malt, 2007). The present findings indicate that a challenge for such models is to explain how domain-general learning mechanisms lead to the development of abstract, domainspecific ontological beliefs prior to the age of 5 . In future work, data on the ontological beliefs of even younger children may help to distinguish between various theoretical accounts of domain specificity in adult cognition.

\section{AUTHOR NOTE}

Funding was provided by NICHD Grant HD-36043 to S.A.G. We are grateful to the children, teachers, and parents who participated in this research, as well as to Amanda Karp and Christine Shenouda for their assistance with data collection. Correspondence concerning this article should be addressed to M. Rhodes, Department of Psychology, New York University, 6 Washington Place, New York, NY 10003 (e-mail: marjorie .rhodes@nyu.edu).

\section{REFERENCES}

Atran, S. (1998). Folk biology and the anthropology of science: Cognitive universals and cultural particulars. Behavioral \& Brain Sciences, 21, 547-569.

Brandone, A. C., \& Gelman, S. A. (2009). Differences in preschoolers' and adults' use of generics about novel animals and artifacts: A window onto a conceptual divide. Cognition, 110, 1-22.

Diesendruck, G., \& Gelman, S. A. (1999). Domain differences in absolute judgments of category membership: Evidence for an essentialist account of categorization. Psychonomic Bulletin \& Review, 6, 338-346.

EsTES, Z. (2003). Domain differences in the structure of artifactual and natural categories. Memory \& Cognition, 31, 199-214.

Estes, Z. (2004). Confidence and gradedness in semantic categorization: Definitely somewhat artifactual, maybe absolutely natural. Psychonomic Bulletin \& Review, 11, 1041-1047.

Fisher, A. V., \& Sloutsky, V. M. (2005). When induction meets memory: Evidence for gradual transition from similarity-based to category-based induction. Child Development, 76, 583-597.

Gelman, R. (1990). First principles organize attention to and learning about relevant data: Number and the animate-inanimate distinction as examples. Cognitive Science, 14, 79-106.

Gelman, S. A. (2003). The essential child: Origins of essentialism in everyday thought. New York: Oxford University Press.

Gelman, S. A., \& Coley, J. D. (1991). Language and categorization: The acquisition of natural kind terms. In S. A. Gelman \& J. P. Byrnes (Eds.), Perspectives on language and thought: Interrelations in development (pp. 146-196). Cambridge: Cambridge University Press.

Gelman, S. A., \& Hirschfeld, L. A. (1999). How biological is essentialism? In D. Medin \& S. Atran (Eds.), Folkbiology (pp. 403-446). Cambridge, MA: MIT Press.

Gelman, S. A., \& Kremer, K. E. (1991). Understanding natural cause: Children's explanations of how objects and their properties originate. Child Development, 62, 396-414.

Gelman, S. A., \& Wellman, H. M. (1991). Insides and essences: Early understandings of the nonobvious. Cognition, 38, 213-244.

Hardin, J. W., \& Hilbe, J. M. (2003). Generalized estimating equations. Boca Raton, FL: CRC Press.

Hatano, G., \& InAGaki, K. (1994). Young children's naive theory of biology. Cognition, 50, 171-188.

KaLish, C. W. (1995). Essentialism and graded membership in animal and artifact categories. Memory \& Cognition, 23, 335-353.

KALISH, C. W. (1998). Natural and artificial kinds: Are children realists or relativists about categories? Developmental Psychology, 34, 376-391.

KeIL, F. C. (1989). Concepts, kinds, and cognitive development. Cambridge, MA: MIT Press, Bradford Books.

MaLt, B. C. (1990). Features and beliefs in the mental representation of categories. Journal of Memory \& Language, 29, 289-315.

MANDLER, J. M., \& MCDonough, L. (1993). Concept formation in infancy. Cognitive Development, 8, 291-318.

PIAGET, J. (1929). The child's conception of the world. London: Routledge \& Kegan Paul.

Rosch, E., Mervis, C. B., Gray, W. D., Johnson, D. M., \& BoyesBraem, P. (1976). Basic objects in natural categories. Cognitive Psychology, 8, 382-439.

Siegel, D. R., \& Callanan, M. A. (2007). Artifacts as conventional objects. Journal of Cognition \& Development, 8, 183-203.

Sloman, S., Lombrozo, T., \& Malt, B. (2007). Ontological commitments and domain specific categorisation. In M. J. Roberts (Ed.), Integrating the mind: Domain general versus domain specific processes in higher cognition (pp. 105-129). Hove, U.K.: Psychology Press.

SlOUTSKY, V. M., \& FisheR, A. V. (2004). Induction and categorization in young children: A similarity-based model. Journal of Experimental Psychology: General, 133, 166-188.

Sloutsky, V. M., Kloos, H., \& Fisher, A. V. (2007). When looks are everything: Similarity versus kind information in early induction. Psychological Science, 18, 179-185.

SмiтH, L. B. (1989). A model of perceptual classification in children and adults. Psychological Review, 96, 125-144.

(Manuscript received December 29, 2008; revision accepted for publication May 8, 2009.) 